\title{
The TraA relaxase autoregulates the putative type IV secretion-like system encoded by the broad- host-range Streptococcus agalactiae plasmid pIP501
}

Correspondence

Elisabeth Grohmann

elisabeth.grohmann@tu-berlin.de

Received 25 August 2005

Revised 15 November 2005

Accepted 17 November 2005
Brigitta Kurenbach, ${ }^{1}$ Jolanta Kopeć, ${ }^{1,2}$ Marion Mägdefrau, ${ }^{1} \dagger$ Kristin Andreas, ${ }^{1}$ Walter Keller, ${ }^{2}$ Christine Bohn, ${ }^{1}$ Mouhammad Y. Abajy ${ }^{1}$ and Elisabeth Grohmann ${ }^{1}$

\author{
1Department for Environmental Microbiology, University of Technology Berlin, FR1-2, \\ Franklinstrasse 28/29, D-10587 Berlin, Germany \\ ${ }^{2}$ Institute for Chemistry, Karl-Franzens-Universität Graz, Heinrichstrasse 28, A-8010 Graz, \\ Austria
}

\begin{abstract}
The conjugative multiple antibiotic resistance plasmid pIP501 can be transferred and stably maintained in a variety of Gram-positive genera, including multicellular Streptomyces lividans, as well as in Gram-negative Escherichia coli. The 15 putative pIP501 transfer (tra) genes are organized in an operon-like structure terminating in a strong transcriptional terminator. This paper reports co-transcription of the pIP501 tra genes in exponentially growing Enterococcus faecalis JH2-2 cells, as shown by RT-PCR. The tra genes are expressed throughout the life cycle of Ent. faecalis, and the expression level is independent of the growth phase. Electrophoretic mobility shift assays indicated that the TraA relaxase, the first gene of the tra operon, binds to the tra promoter $\mathrm{P}_{\text {tra }}$, which partially overlaps with the origin of transfer (oriT). DNase I footprinting experiments further delimited the TraA binding region and defined the nucleotides bound by TraA. $\beta$-Galactosidase assays with $\mathrm{P}_{\text {tra }}-$ lac $Z$ fusions proved $\mathrm{P}_{\text {tra }}$ promoter activity, which was strongly repressed when TraA was supplied in trans. Thus, it is concluded that the pIP501 tra operon is negatively autoregulated at the transcriptional level by the conjugative DNA relaxase TraA.
\end{abstract}

\section{INTRODUCTION}

Plasmid-mediated conjugative transfer of antibiotic resistance genes is one of the major reasons for the tremendous spread of multiple antibiotic resistant pathogenic bacteria. pIP501 is a 30599 bp conjugative Inc18 plasmid, originally isolated from Streptococcus agalactiae (Horodniceanu et al., 1976), conferring resistance to the MLS group of antibiotics (erythromycin) and to chloramphenicol. pIP501 exhibits a very broad host range for conjugative transfer, including streptococci, lactobacilli, enterococci, lactococci, staphylococci, bacilli, Listeria and clostridia. Recently, Zuniga and co-workers have transferred PIP501 and derivatives thereof to Oenococcus oeni, a lactic acid bacterium used as a commercial starter culture, and for which no suitable genetic tools for transfer of exogenous DNA are available (Zuniga et al., 2003). We have demonstrated conjugative transfer of

†Present address: Competence Center for Fluorescence Analysis, Josef-Engert-Strasse 9, D-93053 Regensburg, Germany.

Abbreviations: EMSA, electrophoretic mobility shift assay; GAP-DH, glyceraldehyde-3-phosphate dehydrogenase; G-, Gram negative; G +, Gram positive; GST, glutathione S-transferase.
pIP501 to the multicellular Gram-positive $(G+)$ organism Streptomyces lividans and to the Gram-negative $\left(\mathrm{G}^{-}\right)$organism Escherichia coli. The pIP501 antibiotic resistance, replication and tra genes are functional in the heterologous hosts, and the plasmid is stably maintained for at least 50 generations in E. coli XL-1 Blue cells (Kurenbach et al., 2003).

The pIP501 nic site, at which plasmid DNA transfer initiates by the relaxase-mediated introduction of a site- and strandspecific nick, has been mapped by Wang \& Macrina (1995a). They also proved in vivo nicking activity of the first gene product encoded by the operon, the TraA relaxase (Wang \& Macrina, 1995b). TraA- and TraAN ${ }_{293^{-}}$(the protein comprising the N-terminal 293 amino acids of TraA) mediated in vitro relaxation of supercoiled ori $T_{\mathrm{pIP501}} \mathrm{DNA}$ has been demonstrated by Kurenbach et al. (2002), and relaxation activity of $\mathrm{TraAN}_{246}$ (the protein comprising the $\mathrm{N}$-terminal 246 amino acids of TraA) by Kopeć et al. (2005). The pIP501 relaxase TraA contains a positively charged tail sequence at the $\mathrm{C}$ terminus, as found in putative type IV secretion substrates and in relaxases of conjugative plasmids from various $\alpha$-Proteobacteria (Schulein et al., 2005). $P_{\text {tra }}$ has been mapped by primer extension analysis. Co-transcription of 
the tra genes, orf1 to orf11, has been shown by RT-PCR on RNA from Enterococcus faecalis cells harbouring pIP501 (Kurenbach et al., 2002).

Three of the pIP501 tra genes exhibit significant similarity to type IV secretion system components (Grohmann et al., 2003; Kurenbach et al., 2003) involved in conjugative transfer in G- bacteria (for a review see Llosa \& de la Cruz, 2005) and transport of effector molecules from $\mathrm{G}-$ pathogens to eukaryotic host cells (reviewed by Cascales \& Christie, 2003; Christie, 2004; Christie et al., 2005; Christie \& Cascales, 2005). Possible roles for the type IV homologues in a presumably simplified type IV secretion process through the $\mathrm{G}+$ cell envelope have been discussed in Grohmann et al. (2003) and Grohmann (2005).

Regulation of conjugative transfer has been studied in some detail for $\mathrm{G}-$ bacteria, whereas in $\mathrm{G}+$ bacteria knowledge of regulation of conjugative transfer is mainly based on data of the Ent. faecalis sex-pheromone-responding conjugative plasmids pCF10, pAD1 and pPD1 (Bae \& Dunny, 2001; Bae et al., 2002, 2004; Horii et al., 2002; for reviews see Clewell \& Dunny, 2002; Chandler \& Dunny, 2004).

In this report, we present data on the regulation of the pIP501 tra operon (Fig. 1). By two different approaches we demonstrate that the regulation is exerted at the transcriptional level: i) $\mathrm{P}_{\text {tra }}$ : : lacZ reporter fusions proved repression of the tra operon promoter in the presence of the TraA DNA relaxase; and ii) electrophoretic mobility shift assays (EMSAs) and DNase I protection experiments showed binding of TraA to DNA fragments containing the tra operon promoter and parts thereof.

\section{METHODS}

Bacterial strains and growth conditions. Ent. faecalis $\mathrm{JH} 2-2$ (Jacob \& Hobbs, 1974) was cultivated in brain heart infusion medium (Oxoid) at $37^{\circ} \mathrm{C}$. For the selection of Ent. faecalis JH2-2 (pIP501), $20 \mu \mathrm{g}$ chloramphenicol $\mathrm{ml}^{-1}$ was added to the medium. E. coli JM109 (Promega) and E. coli HB101 (Promega) were grown in $\mathrm{LB}$ medium at $37^{\circ} \mathrm{C}$, supplemented with $100 \mu \mathrm{g}$ ampicillin $\mathrm{ml}^{-1}$ for the selection of pQE30-traAN $N_{246}$ (Kopeć et al., 2005) and pQF120 (Ronald et al., 1990) and derivatives thereof. LB medium was supplemented with $20 \mu \mathrm{g}$ chloramphenicol ml ${ }^{-1}$ and $10 \mu \mathrm{g}$ tetracycline $\mathrm{ml}^{-1}$ for the selection of pACYC184, and supplemented with $20 \mu \mathrm{g}$ chloramphenicol ml $\mathrm{m}^{-1}$ alone for derivatives thereof. For the $\beta$-galactosidase assays, E. coli JM109 cells harbouring the respective plasmids were cultivated in the medium suggested by Miller (1972).

DNA preparation and transformation. Extraction and purification of plasmid DNAs from E. coli were performed using the Qiagen kit or the Gen Elute Plasmid Miniprep kit (Sigma). Restriction endonucleases were purchased from Promega and New England Biolabs, T4 DNA ligase and Shrimp alkaline phosphatase from Roche Diagnostics, and Gen Therm DNA polymerase from Rapidozym. The enzymes were used as specified by the suppliers. PCR fragments for cloning experiments were purified by Wizard PCR Preps (Promega). Preparation of competent cells and E. coli transformations with plasmid DNA were performed by standard methods (Sambrook et al., 1989).

Construction of plasmids for the $\boldsymbol{\beta}$-galactosidase assay. The promoter probe plasmid pQF120 containing a promoterless lacZ gene was used to clone $\mathrm{P}_{\text {tra. }} \mathrm{P}_{\text {tra }}$ was amplified as a 179 bp PCR fragment with the oligonucleotide primers Ptra_fw and Ptra_rev with added BglII restriction sites at their $5^{\prime}$ ends and a lysate of Ent. faecalis JH2-2 (pIP501) as template. All oligonucleotides used in this work are listed in Table 1 . The 171 bp BglII-BglII fragment was ligated with BglII-cut and dephosphorylated pQF120 (9200 bp). E. coli JM109 cells harbouring recombinant plasmids (pQF120-P tra)

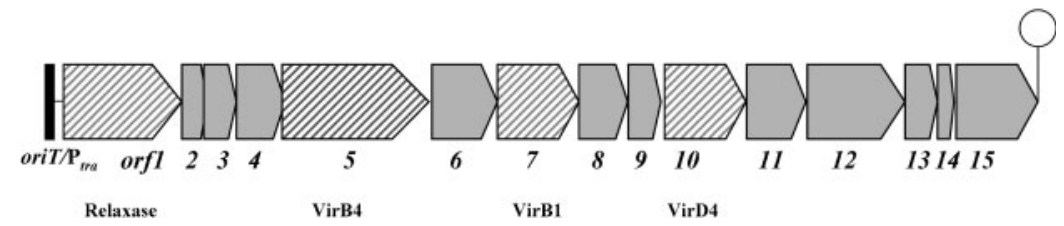

Fig. 1. Organization of the pIP501 tra region. The overlapping oriT and $\mathrm{P}_{\text {tra }}$ regions are indicated (not to scale). The operon (orf1 to orf15) is terminated by a putative strong rhoindependent termination signal (hairpin). Hatched genes encode proteins similar to those identified in G- type IV secretion systems. The ORF5 protein shows the conserved features, a nucleotide binding site motif $A$ (Walker A box ${ }_{250}$ GLSGGGKT $_{256}$ ) and motif B (Walker B box ${ }_{509}$ DEFHFLL $_{515}$ ), of proteins belonging to the VirB4 family of NTP-binding proteins (COG3451). The ORF10 protein is a member of the pfam02534 family of TraG/ TrwB/TraD/VirD4 coupling proteins. It shows the P-loop motif (Walker A box) and a Walker $\mathrm{B}$ motif for nucleotide binding. The ORF7 protein (similar to VirB1 of the Agrobacterium T DNA transfer system) contains the SLT domain present in bacterial lytic transglycosylases. This domain catalyses the cleavage of the $\beta$-1,4-glycosidic bond between acetylmuramic acid and $\mathrm{N}$-acetylglucosamine in the cell wall. 
Table 1. Oligonucleotides used in this work

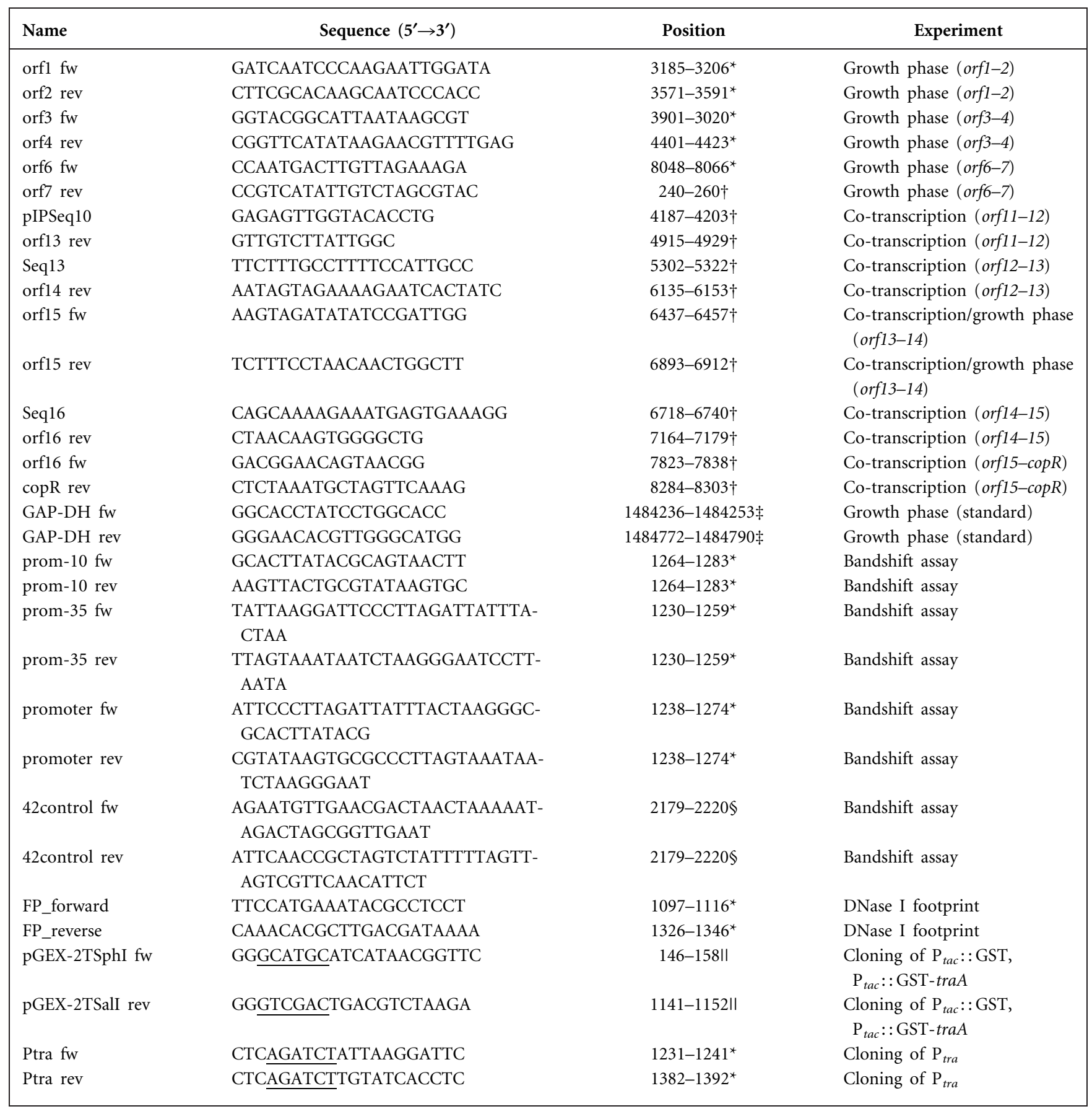

Accession nos: ${ }^{\star}$ L39769, †AJ505823, $¥$ NC_004668 (locus EF1526), §AJ301605, ॥U13850. Restriction sites are underlined.

were selected as blue colonies on LB agar plates supplemented with

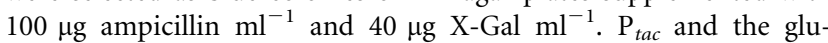
tathione $S$-transferase gene $\left(\mathrm{P}_{t a c}: \mathrm{GST}\right)$ were PCR-amplified from pGEX-2T (Amersham Biosciences) with primers containing Sall and SphI restriction sites at the $5^{\prime}$ ends, respectively; the fragment was cut with SalI/SphI and inserted into the respective sites of pACYC184 (Chang \& Cohen, 1978), thereby interrupting the tetracycline-resistance gene. The traA expression cassette $\left(\mathrm{P}_{\text {tac }}:\right.$ :GSTtraA) was amplified from pGEX-2T-traA (Kurenbach et al., 2002) with the same primers and inserted into the SalI/SphI sites of
pACYC184. Transformants resistant to chloramphenicol but sensitive to tetracycline were PCR-verified for the presence of $P_{t a c}:$ GST and $\mathrm{P}_{t a c}:$ :GST-traA, respectively. The nucleotide sequence of the insertions was verified by dideoxy chain termination sequencing in an automated sequencer (ABI prism 310, Perkin Elmer).

$\boldsymbol{\beta}$-Galactosidase assay. Samples were taken from exponentially growing cultures $\left(\mathrm{OD}_{600}=0 \cdot 3\right)$ in a minimal medium. Cells were permeabilized by the addition of chloroform and $0 \cdot 1 \%$ SDS. The expression of $\operatorname{tra} A$ was induced by addition of $1 \mathrm{mM}$ IPTG (time of 
induction $4 \mathrm{~h}$ ) to E. coli JM109 cultures harbouring pACYC184$\mathrm{P}_{\text {tac }}$ : : GST-traA. Determination of $\beta$-galactosidase activity was performed as described by Miller (1972).

Estimation of plasmid copy number. Aliquots taken from cultures at the time of sampling for $\beta$-galactosidase assays were lysed, and plasmid DNA was prepared with the Gen Elute Plasmid Miniprep kit (Sigma) and analysed on $0.7 \%$ agarose gels. The gels were stained and the amount of plasmid DNA per unit of culture optical density quantified by the Easy win 32 software (Herolab).

RT-PCR analysis. RNA of exponentially growing Ent. faecalis JH22 and Ent. faecalis JH2-2 cells harbouring pIP501 $\left(\mathrm{OD}_{600}=0 \cdot 6\right)$ was isolated and purified as described in Kurenbach et al. (2002). RTPCR was performed with primer pairs designed to amplify two successive ORFs (orf11 to orf15) in the pIP501 tra region. Prior to use in RT-PCR, RNA was treated with DNase I (Promega). A $0.5 \mu \mathrm{g}$ quantity of RNA and 50 pmol of each primer were used in each RTPCR performed with the Access-RT-PCR kit (Promega). RNA samples were denatured for $2 \mathrm{~min}$ at $70{ }^{\circ} \mathrm{C}$ and kept on ice prior to addition of polymerases. The orf 11 to orf 12 fragment was amplified as follows: $48{ }^{\circ} \mathrm{C}$ for $60 \mathrm{~min}$ for reverse transcription, followed by inactivation of avian myeloblastosis virus reverse transcriptase (AMV-RT) and denaturation of the template at $94^{\circ} \mathrm{C}$ for $90 \mathrm{~s}$. The program $94{ }^{\circ} \mathrm{C}$ for $30 \mathrm{~s} / 55^{\circ} \mathrm{C}$ for $90 \mathrm{~s} / 68^{\circ} \mathrm{C}$ for $4 \mathrm{~min}$ was applied (40 cycles) and terminated by a final elongation step of $10 \mathrm{~min}$. For the amplification of orf12 to orf13, orf13 to orf14, orf14 to orf15, and orf 15 to $\operatorname{cop} R$, the program $94^{\circ} \mathrm{C}$ for $30 \mathrm{~s} / 60^{\circ} \mathrm{C}$ for $90 \mathrm{~s} / 68^{\circ} \mathrm{C}$ for 2 min ( 30 cycles) was applied and terminated by a final elongation step of $10 \mathrm{~min}$. Control reactions were performed with RNA from the plasmid-free isogenic strain, without template RNA, and with template RNA but omitting the reverse transcription step (data not shown). RT-PCR products were analysed on $2 \%$ agarose gels.

RT-PCR of tra mRNA isolated under different growth conditions. Total RNA was isolated from Ent. faecalis JH2-2 (pIP501) cells harvested at different stages of bacterial growth: in the early exponential phase, $\mathrm{OD}_{600}=0 \cdot 2$; in the mid-exponential phase, $\mathrm{OD}_{600}=0 \cdot 6$; and during the stationary growth phase, $\mathrm{OD}_{600}=1 \cdot 0$. The semi-quantitative RT-PCR was performed in two steps. i) Reverse transcription (cDNA synthesis): $2 \mu \mathrm{l}$ DNase-treated RNA was incubated with $0.5 \mu \mathrm{g}$ random hexamer primer (Promega) in a volume of $5 \mu \mathrm{l}$ for $5 \mathrm{~min}$ at $70^{\circ} \mathrm{C}$, and then stored on ice. dNTPs (10 pmol), $2 \mathrm{mM} \mathrm{MgCl} 2,4 \mu \mathrm{l} 5 \times \mathrm{M}$-MLV buffer and $1 \mu \mathrm{l} \mathrm{M-MLV}$ (Moloney murine leukaemia virus) reverse transcriptase and diethyl pyrocarbonate-treated water were added to a final volume of $20 \mu \mathrm{l}$ and incubated for $5 \mathrm{~min}$ at $25^{\circ} \mathrm{C}, 60 \mathrm{~min}$ at $42^{\circ} \mathrm{C}$ and $15 \mathrm{~min}$ at $70{ }^{\circ} \mathrm{C}$; cDNA was purified by ethanol precipitation. The DNA concentration was determined by $A_{260}$ measurement and calculated by using the online help (www.promega.com/biomath) for singlestrand DNA calculations. ii) PCR: $1 \mu \mathrm{g}$ cDNA was applied to PCRs containing $2 \mathrm{mM} \mathrm{MgCl} 2,10$ pmol dNTPs, $5 \mu \mathrm{l} 10 \times$ PCR buffer, $1.5 \mathrm{U}$ Gentherm DNA polymerase and $20 \mathrm{pmol}$ of each primer in a total volume of $50 \mu \mathrm{l}$. For amplification of orf1 to orf2, orf6 to orf7, and orf13 to orf14, the cycle program $94{ }^{\circ} \mathrm{C}$ for $30 \mathrm{~s} / 60^{\circ} \mathrm{C}$ for $90 \mathrm{~s} /$ $68^{\circ} \mathrm{C}$ for $2 \mathrm{~min}(30$ cycles) was applied and terminated by a final elongation step of $10 \mathrm{~min}$. As a constitutively expressed control, the glyceraldehyde-3-phosphate dehydrogenase (GAP-DH) gene was reverse transcribed and amplified by the same procedure. For amplification of orf 3 to orf4 and the gene encoding GAP-DH, the annealing temperature was decreased to $56{ }^{\circ} \mathrm{C}$. The PCR products were analysed in $1.5 \%$ agarose gels and quantified by the Easy win 32 software (Herolab).

DNA labelling. Synthetic oligonucleotides were purchased from VBC-GENOMICS and Sigma-Genosys. They were labelled with $\left[\gamma^{32} \mathrm{P}\right]$ ATP $\left(1 \cdot 11 \times 10^{14} \mathrm{~Bq} \mathrm{mmol}^{-1}\right)$ by $\mathrm{T} 4$ polynucleotide kinase (Roche Diagnostics). Unbound $\left[\gamma^{32} \mathrm{P}\right] \mathrm{ATP}$ was removed by a Sephadex
G-50 (Amersham Biosciences) column. For EMSAs, the 5' endlabelled oligonucleotides were annealed to the complementary unlabelled oligonucleotide to generate double-stranded DNA. A 1:1 mixture of the oligonucleotides was diluted in Tris/EDTA buffer $(10: 1)$, completely denatured $\left(5 \mathrm{~min}\right.$ at $\left.95^{\circ} \mathrm{C}\right)$ and annealed by slowly cooling down to room temperature. The labelled DNA fragments were applied immediately to the EMSAs or stored at $4{ }^{\circ} \mathrm{C}$.

EMSAs. TraAN 246 was overexpressed and purified as described in Kopeć et al. (2005). All oligonucleotides used to generate doublestranded DNA fragments are shown in Table 1. Binding mixtures $(20 \mu \mathrm{l})$ containing $10 \mathrm{fmol}$ radiolabelled DNA fragment and increasing $\mathrm{TraAN}_{246}$ concentrations in $20 \mathrm{mM}$ Tris/ $\mathrm{HCl}, \mathrm{pH} 7 \cdot 5,0 \cdot 1 \mathrm{mM}$ EDTA, $200 \mathrm{mM} \mathrm{NaCl}$, were incubated at $37^{\circ} \mathrm{C}$. Binding reactions and electrophoresis were performed as described in Kopeć et al. (2005). As a negative control, a randomly chosen 42-mer DNA fragment with no sequence identity with the pIP501 promoter region (nucleotides 2179 to 2220 on pIP501, accession no. AJ301605) was incubated with increasing $\operatorname{TraAN}_{246}$ concentrations up to $4 \mu \mathrm{M}$. No binding was observed.

DNase I footprint. 5'-Labelled FP_forward and unlabelled FP_ reverse primer or $5^{\prime}$-labelled $\mathrm{FP}$ _reverse and unlabelled $\mathrm{FP}$ _forward primer were used to generate a $250 \mathrm{bp} \mathrm{P}_{\text {tra }}$ and oriT DNA fragment (nucleotides 1097 to 1346, accession no. L39769) with labelled coding and non-coding strands.

Prior to the DNase I footprint reaction, the fragments were heated to $95^{\circ} \mathrm{C}$ for $10 \mathrm{~min}$ and allowed to cool to $37^{\circ} \mathrm{C}$. TraA was purified as described in Kopeć et al. (2005). Ten nanograms of the $250 \mathrm{bp}$ fragment $(6.5 \mathrm{nM})$ were incubated at $37^{\circ} \mathrm{C}$ for $10 \mathrm{~min}$ with increasing TraA concentrations from $200 \mathrm{nM}$ to $2 \mu \mathrm{M}$ in binding buffer $(20 \mathrm{mM}$ Tris/ $\mathrm{HCl}, \mathrm{pH} 8 \cdot 0,200 \mathrm{mM} \mathrm{NaCl}, 0 \cdot 1 \mathrm{mM}$ EDTA) in a total volume of $10 \mu$ l. DNase I $(0.01 \mathrm{Kunitz}$ units, Fermentas) was added to each sample. Ten microlitres of stop buffer $\left(100 \mu \mathrm{g}\right.$ yeast tRNA ml ${ }^{-1}$, 30 mM EDTA, $1 \%$ SDS, $200 \mathrm{mM} \mathrm{NaCl}$ ) (Leblanc \& Moss, 1994) were added to naked DNA after $1 \mathrm{~min}$, and to reactions with TraA after $3 \mathrm{~min}$. DNA was extracted with phenol/chloroform/isoamyl alcohol $(25: 24: 1$, by volume $)$ and precipitated with ethanol. The pellets were air-dried, dissolved in loading buffer $(33 \mathrm{mM} \mathrm{NaOH}, 32 \%$ formamide, $0 \cdot 1 \%$ bromophenol blue, $0 \cdot 1 \%$ xylene cyanol) and run on a $5 \%$ denaturing polyacrylamide gel with $8 \mathrm{M}$ urea in $1 \times$ TBE buffer at constant wattage. Reference sequencing reactions were prepared with the Cycle Sequencing kit (Fermentas) with primers FP_forward and FP_reverse. Only the nucleotide numbers are shown in Fig. 5. The gel was exposed overnight to a Storage Phosphor GP Screen (Amersham Biosciences) and read by the Typhoon 9400 imaging system (Amersham Biosciences).

\section{RESULTS AND DISCUSSION}

\section{The pIP501 tra region is transcribed as a single operon in Ent. faecalis}

The pIP501 tra region shows an operon-like structure [short distance between translational stop and start codons of neighbouring genes, overlapping stop (orf11) and start codons (orf12)]. In order to test co-transcription of orf1 to orf15, we performed RT-PCR with RNA isolated from Ent. faecalis JH2-2 (pIP501) cells harvested during the midexponential growth phase, at $\mathrm{OD}_{600}=0 \cdot 6$. Primer pairs were selected to amplify two successive genes of the pIP501 tra region, starting with orf11. Co-transcription of orf1 to orf11 has already been demonstrated (Kurenbach et al., 2002). 
RT-PCR resulted in products of the expected size for orf 11 to $\operatorname{orf12}$ orf12 to orf13, orf13 to orf14, and orf14 to orf15 (Fig. 2, lanes 1, 2, 3 and 4). We tested for the existence of transcription products beyond orf 15 using primers which would generate an orf15/copR product of $480 \mathrm{bp}$. Using RNA as template, the respective product was never observed (Fig. 2, lane 5). Transcription of the pIP501 tra operon appears to be terminated by a strong rho-independent transcriptional terminator [free energy of about $-46 \mathrm{~kJ}$ $\mathrm{mol}^{-1}$, for the following setting: DNA sequence at $37^{\circ} \mathrm{C}$, $1 \mathrm{M} \mathrm{NaCl}$; MFold web server for nucleic acid folding and hybridization prediction: http://www.bioinfo.rpi.edu/ applications/mfold (Zuker, 2003)] approximately $10 \mathrm{bp}$ downstream of the orf 15 translational stop codon (data not shown).

\section{The expression level of the tra genes is independent of growth phase}

To investigate the potential influence of growth phase on the expression level of the tra genes, total RNA from Ent. faecalis JH2-2 (pIP501) was isolated at three different time-points of growth: in the early exponential $\left(\mathrm{OD}_{600}=0 \cdot 2\right)$, the midexponential $\left(\mathrm{OD}_{600}=0 \cdot 6\right)$, and the stationary growth phase $\left(\mathrm{OD}_{600}=1 \cdot 0\right)$. First, we tested if the tra genes are expressed

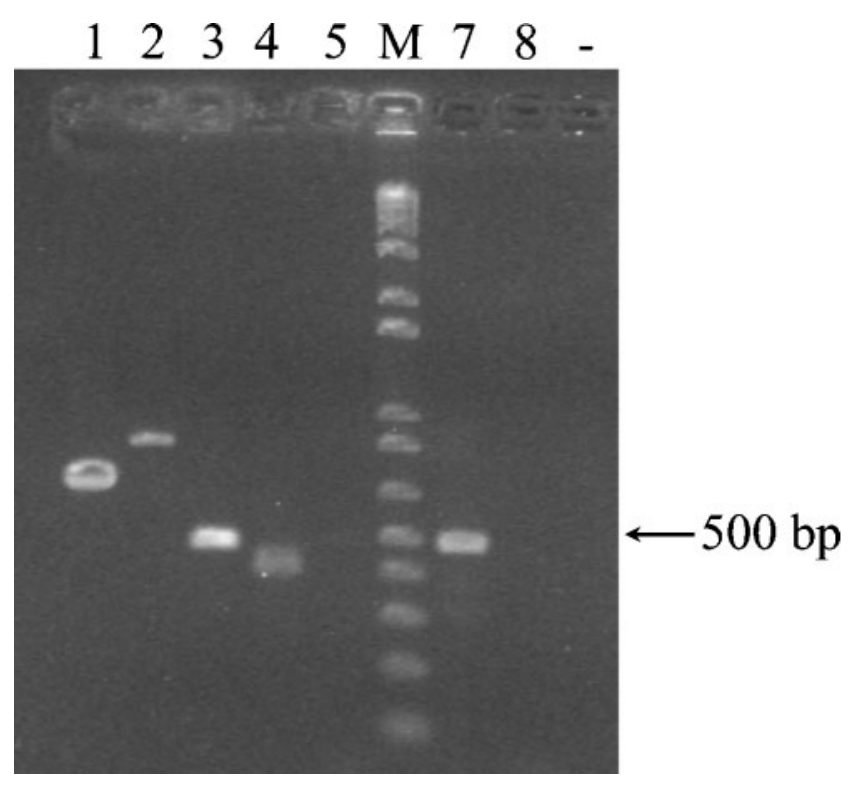

Fig. 2. Co-transcription of orf11 to orf15 of the tra region of pIP501. PCR products were loaded onto a $2 \%$ agarose gel. The expected product size is given below in parentheses. Lane 1, orf11 to orf12 (690 bp); lane 2, orf12 to orf13 (852 bp); lane 3 , orf13 to orf14 (474 bp); lane 4 , orf14 to orf15 (461 bp); lane 5, orf15 to $\operatorname{copR}(480 \mathrm{bp}) ; \mathrm{M}, 1 \mathrm{~kb}$ Plus DNA ladder (Invitrogen); lane 7, orf15 to $\operatorname{cop} R$, PCR with lysed cells of Ent. faecalis JH2-2 (pIP501); lane 8, orf15 to copR, PCR with lysed cells of Ent. faecalis JH2-2 (plasmid free); -, negative control, orf15 to copR (without template). in all three growth phases. The selected RT-PCR products from orf3 to orf4, orf6 to orf7, and orf13 to orf14 were obtained with RNA from all three growth phases. For the semi-quantitative RT-PCRs, $2 \mu$ l each RNA sample was subjected to reverse transcription reactions. The cDNA obtained was quantified by $A_{260}$ measurement. The amount of cDNA template for PCR was selected taking two requirements into account: i) the amount of cDNA had to be under the level of saturation of the respective PCRs; and ii) the amount of cDNA should yield good visible and quantifiable PCR products. The use of $1 \mu \mathrm{g}$ of each cDNA fulfilled both criteria. Amplification of products from orf1 to orf2, and orf13 to orf14, of the pIP501 tra region was chosen to investigate the expression levels of different tra genes under varying physiological conditions. As a control, the constitutively expressed gene for GAP-DH was also amplified by RT-PCR, applying RNA isolated from Ent. faecalis JH2-2 cells harvested at $\mathrm{OD}_{600}=0 \cdot 2,0 \cdot 6$ and $1 \cdot 0$ as template. Identical volumes of PCR samples were loaded onto $1.5 \%$ agarose gels and subjected to electrophoresis. In Fig. 3, PCR samples of orf1 to orf2, orf 13 to orf14, and GAP-DH are shown. The amounts of obtained PCR products were compared for the different tra gene fusions at the three different time-points by quantification of the DNA bands with Easy win 32 software. No significant differences were detected for the analysed PCR products. The constitutively expressed gene for GAP-DH yielded the same amount of PCR product under all the conditions tested.

The only variable parameter in the experiment was the growth phase of the Ent. faecalis JH2-2 (pIP501) cells. We cannot exclude, however, that tra gene expression decreases at a later stage in stationary phase, as we have observed slightly lower transfer frequencies (two- to threefold decrease) for donors and/or recipients grown to high cell densities $\left(\mathrm{OD}_{600}>1 \cdot 1\right.$; C. Bohn and E. Grohmann, unpublished observations). However, a phenomenon such as ' $\mathrm{F}$ ' phenocopies', in which $\mathrm{F}^{+}$cells become transfer-deficient in stationary phase (Hayes, 1964), was never observed. The expression of several F-encoded tra genes decreases at the transcriptional level in mid-exponential or stationary phase, coincident with a rapid decline in transfer efficiency in mid-exponential phase (Frost \& Manchak, 1998).

We conclude that the pIP501 tra genes are expressed during the whole growth cycle of Ent. faecalis and that their level of expression is independent of growth phase.

\section{The TraA relaxase binds to the $\mathbf{P}_{\text {tra }}$ promoter}

The compact organization of the PIP501 oriT region (Fig. 4), in the sense that the $\mathrm{P}_{\text {tra }}-10$ and -35 boxes overlap with the left half repeat of inverted repeat structures (IR-1 and IR-2), presumably representing the TraA recognition and binding site (Kopeć et al., 2005), makes autoregulation of the tra operon by the TraA relaxase likely. To study relaxase binding to the $\mathrm{P}_{\text {tra }}$ promoter, we selected three DNA fragments, the first comprising the whole promoter $(-35$ and -10 region), the second the -35 region alone, and the 


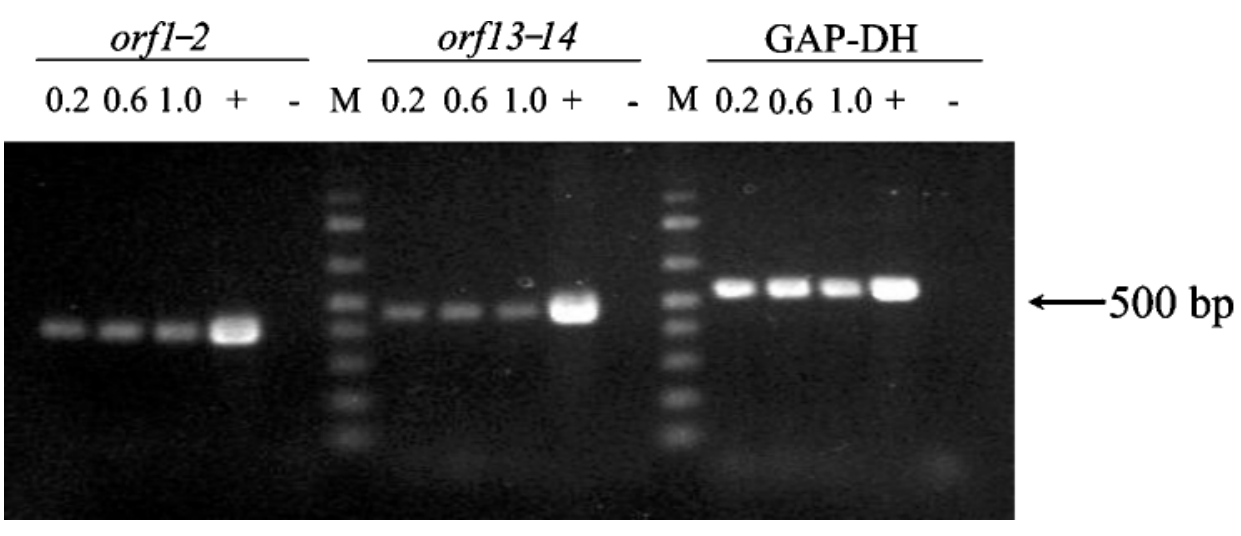

Fig. 3. $P C R$ with cDNA from Ent. faecalis JH2-2 (pIP501). PCR product $(2 \mu \mathrm{l}$ ) was loaded onto a $1.5 \%$ agarose gel. cDNA $(1 \mu \mathrm{g}$ ) was used in two tra-specific PCRs (orf1 to orf2, $404 \mathrm{bp}$ product; orf13 to orf14, 474 bp product) and a PCR specific for the GAP-DH of Ent. faecalis (555 bp product). RNA was isolated at $\mathrm{OD}_{600}=0 \cdot 2,0 \cdot 6$ and $1 \cdot 0$. M, $100 \mathrm{bp}$ DNA ladder (Invitrogen); +, positive control with lysed cells of Ent. faecalis JH2-2 (pIP501); -, negative control without template.

third the -10 region alone. The shortest $\mathrm{N}$-terminal portion of TraA exhibiting relaxase activity, the 246 amino acid $\mathrm{TraAN}_{246}$ protein (Kopeć et al., 2005), was used in the bandshift assays. The oligonucleotide representing the tra coding strand was $5^{\prime}$ labelled and annealed to the complementary unlabelled strand to generate doublestranded substrates for the EMSAs. As an example, the data for the -10 region fragment are shown. Applying increasing $\operatorname{TraAN}_{246}$ concentrations to this fragment, we detected one retarded DNA-protein complex (Fig. 4).
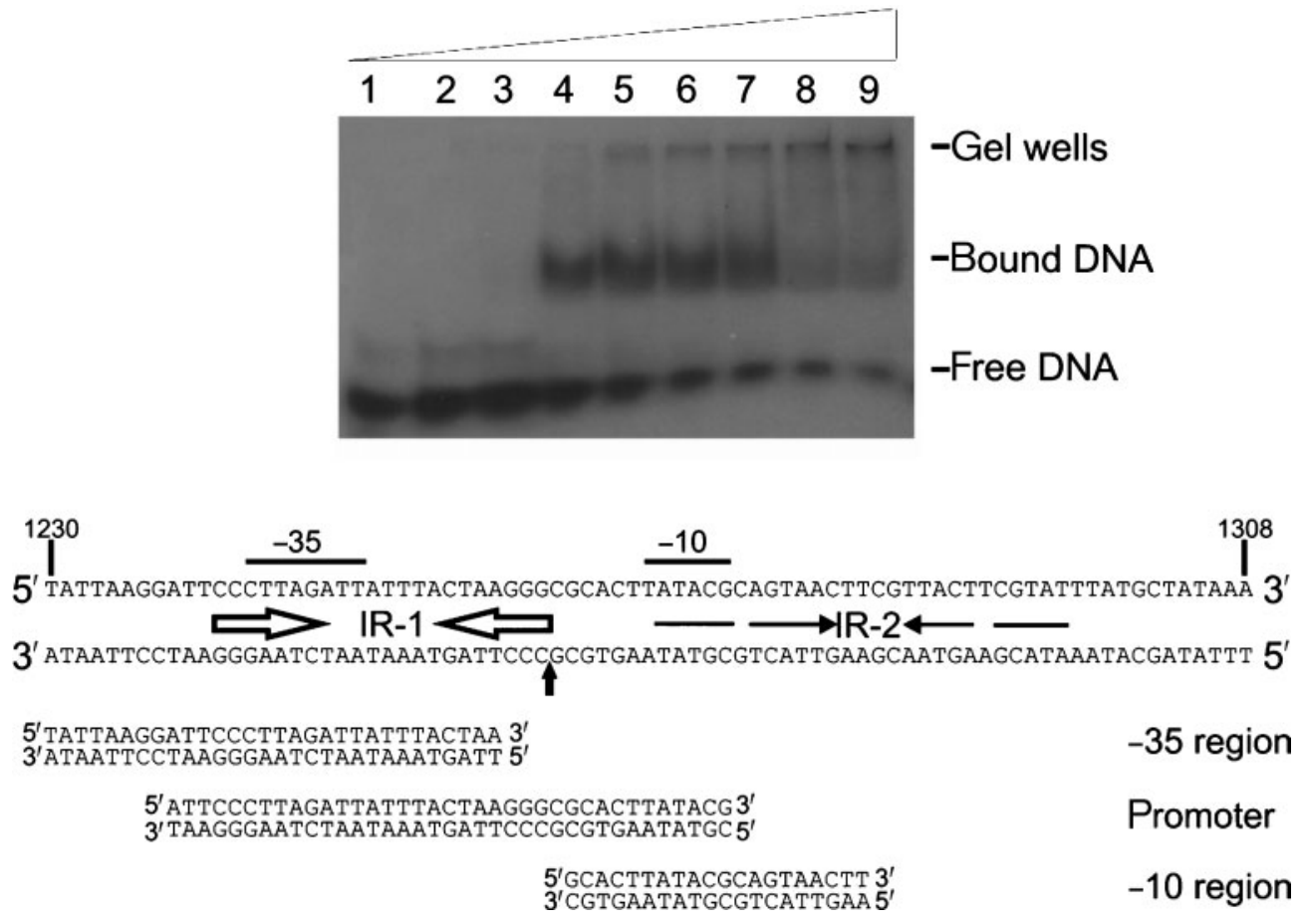

Fig. 4. $E M S A$ of the -10 promoter region fragment with $\operatorname{TraAN}_{246}$. Increasing $\operatorname{TraAN}_{246}$ concentrations $(0,5,50,200,350$, $500,650,800 \mathrm{nM}, 1 \mu \mathrm{M})$ were incubated with $10 \mathrm{fmol}$ DNA of the -10 promoter region fragment at $42{ }^{\circ} \mathrm{C}$ for $30 \mathrm{~min}$, and loaded onto a $10 \%$ native polyacrylamide gel. The ori $T_{\text {pIP501 }}$ region, containing the $\mathrm{P}_{\text {tra }}$ promoter, a perfect inverted repeat (IR-1) (open horizontal arrows), an imperfect inverted repeat (IR-2) (solid horizontal arrows) and the nic site (vertical arrow), is indicated. The promoter fragment and the -35 DNA fragment are also shown. 

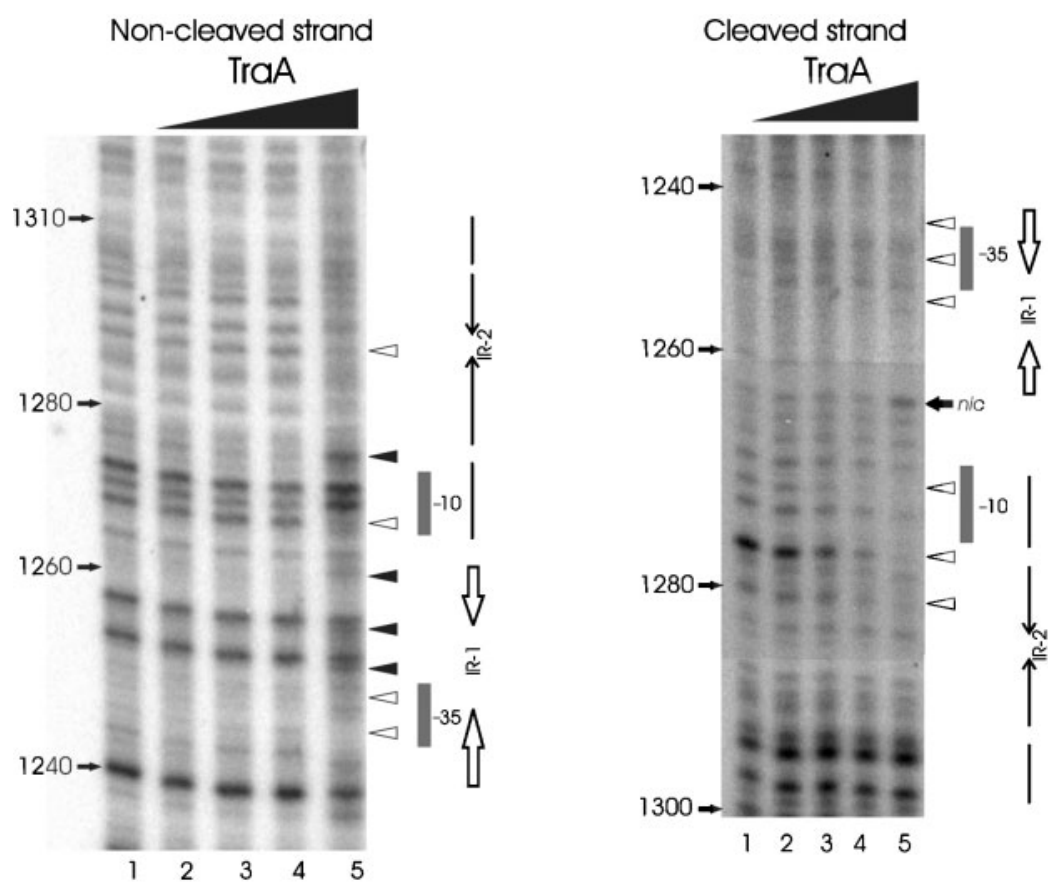

Fig. 5. DNase I footprinting analysis of the oriT region of pIP501. One hundred nanograms of the $250 \mathrm{bp}$ oriT fragment were incubated with increasing TraA concentrations: lane 1, no TraA added; lane 2, $200 \mathrm{nM} \mathrm{TraA}$; lane 3, $500 \mathrm{nM}$ TraA; lane 4, $1 \mu \mathrm{M}$ TraA; lane 5, $2 \mu \mathrm{M}$ TraA. The nucleotide positions on the pIP501 sequence (accession no. L39769) are shown on the left; the -10 and $-35 \mathrm{P}_{\text {tra }}$ regions are marked by filled rectangles. The open and solid arrows indicate the inverted repeats IR-1 and IR-2, respectively. The open and solid arrowheads to the right of each panel show the bands decreased and increased in intensity, respectively, with increasing concentrations of TraA. The nic site is marked with a horizontal arrow. In the right-hand panel, the gel image is composed of three parts with different brightness and contrast for better clarity.

Incubation of the -35 region and the promoter fragment with $\mathrm{TraAN}_{246}$ concentrations of greater than $1 \cdot 0 \mu \mathrm{M}$ resulted in a complete shift, which represented large protein-DNA complexes that were excluded and so did not enter the gel. Binding affinity for the -35 region and for the whole promoter region was lower than for the -10 region fragment (data not shown). This could be due to presence of the complete left half repeat of the inverted repeat structure (IR-2) in the -10 region fragment.

The complete left half repeat of IR-2 was present in all singlestrand oligonucleotides shown to bind TraAN $\mathrm{T}_{246}$ and TraA. An oligonucleotide comparable with the -10 region fragment, but additionally containing the right half repeat, results in similar binding affinity (Kopeć et al., 2005). TraA showed similar binding affinities for the different promoter fragments to those of the N-terminal domain $\operatorname{TraAN}_{246}$ (data not shown).

Incubation of $\mathrm{TraAN}_{246}$ at concentrations up to $4 \mu \mathrm{M}$ with a 42-mer control fragment (8000-fold excess of protein) resulted in no visible shift (data not shown). We conclude that the TraA DNA relaxase binds to the $\mathrm{P}_{\text {tra }}$ promoter region. This is in good agreement with relaxase binding to oligonucleotides composed of i) the complete IR-2 structure, ii) IR-2 and the region up to the nic site, and iii) IR-2, the nic site and seven further $5^{\prime}$ bases (Kopeć et al., 2005).

DNase I footprinting analyses with a $250 \mathrm{bp}$ DNA fragment composed of $\mathrm{P}_{\text {tra }}$ and the complete IR- 1 and IR-2 structures showed protection of both the $\mathrm{P}_{\text {tra }}-35$ region and the -10 region, with hypersensitive sites on the non-cleaved strand close to the nic site (nucleotide numbers 1253 and
1256), at the nic site (nucleotide number 1262) and two nucleotides downstream from the -10 region. On the cleaved strand, DNase I protection extends eight nucleotides to the nic site, with the nic site itself as hypersensitive site (Fig. 5). The DNase I hypersensitive sites could be generated by a conformational change of the oriT region induced by TraA binding, resulting in greater exposure to DNase I attack.

Our data indicate that the left half repeats of IR-1 and IR-2 are the preferential binding sites for the TraA relaxase. Binding of TraA to its target DNA would be a prerequisite for the recognition and cleavage of DNA at the $5^{\prime}-\mathrm{GpC}-3^{\prime}$ dinucleotide in the nic site, which would remain accessible to the enzymic activity of TraA.

\section{Autoregulation of the tra operon: the TraA relaxase negatively regulates transcription from the $\mathbf{P}_{\text {tra }}$ promoter}

To prove that TraA binding to the $\mathrm{P}_{\text {tra }}$ promoter region affects promoter activity, we put the promoterless lac $Z$ gene in pQF120 under the control of the $\mathrm{P}_{\text {tra }}$ promoter. E. coli JM109 cells harbouring this construct, pQF120$\mathrm{P}_{\text {tra }}$ : lacZ, gave blue colonies on LB X-Gal plates and resulted in a $\beta$-galactosidase activity of 401 Miller units. The effect of traA expression in trans on $\mathrm{P}_{\text {tra }}$ activity was tested by co-transformation of E. coli JM109 cells with pQF120-P $\mathrm{P}_{\text {tra }}$ : : lacZ and pACYC184-P tac : GST-traA expressing traA under the control of the IPTG-inducible tac promoter. When traA expression was induced by the addition of $1 \mathrm{mM}$ IPTG, the $\beta$-galactosidase activity dropped to 6 Miller units. As a control, the effect of co-resident pACYC184- $\mathrm{P}_{t a c}:$ :GST on the $\mathrm{P}_{\text {tra }}$ activity of 
pQF120- $\mathrm{P}_{\text {tra }}:$ : lacZ was tested. No significant change in $\beta$-galactosidase activity (407 Miller units) was observed. The copy number of the pACYC184 derivatives (pACYC184$\mathrm{P}_{t a c}:$ :GST and pACYC184- $\mathrm{P}_{\text {tac }}:$ : GST-traA) is considerably smaller (10-12 copies per cell) than that of pQF120$\mathrm{P}_{\text {tra }}$ : : lacZ (500-700 copies per cell, pMB1 ori of pUC18). The $\beta$-galactosidase activities were corrected for apparent copy-number variations. The data (mean values of three independent measurements) clearly indicate that the tra operon is regulated at the level of transcription by the TraA relaxase.

The compact organization of the pIP501 oriT region: partial overlapping of relaxase promoter and nic-region, resembles that of the rolling-circle-replicating plasmid pMV158 (Farías et al., 1999; Grohmann et al., 1999), which is efficiently mobilized by pIP501 (van der Lelie et al., 1990; Kurenbach et al., 2003). For the pMV158-encoded relaxase MobM, autoregulation is currently under investigation. de Antonio and co-workers have proposed that a Leuzipper motif between residues 317 and 338 in MobM might be involved in dimerization and autoregulation (de Antonio et al., 2004). In TraA, no putative Leu-zipper motif was found. For Mob, the mobilization protein encoded by the mobilizable broad-host-range plasmid pBBR1, the nic site of which is identical with that of pMV158, autoregulation by the binding of Mob to its promoter region overlapping with oriT has been demonstrated (Szpirer et al., 2001).

Autoregulation of tra gene expression mediated by the transfer initiator protein, the DNA relaxase, seems to be an effective mechanism to shut down the energy-consuming process of plasmid transfer in a controlled way at a very early stage of plasmid spread. It has been demonstrated that this mechanism is not restricted to small non-selftransmissible plasmids, but seems also to control the conjugative transfer of multiple resistance plasmids of $\mathrm{G}+$ origin (pIP501 and pRE25, the transfer region of which is virtually identical to that of pIP501). All these transfercontrol systems as well as those from $\mathrm{G}-$ bacteria appear to be designed to achieve an optimum balance between the maximum transfer potential and the lowest metabolic burden for the host.

\section{ACKNOWLEDGEMENTS}

We are very grateful to E. Zechner and S. Kohlwein (Karl-FranzensUniversity Graz) for providing access to the radioisotope experimental facility and the Typhoon 9400 imaging system, respectively. This work was supported by the Deutsche Forschungsgemeinschaft, grants GR1792/1-1 and 1-2, the Austrian Science Foundation (FWF projects P15040 and F01805) and by travel grants of the Deutscher Akademischer Austauschdienst (DAAD) and the Dr Heinrich JörgStiftung. The generous support of the Institute of Ecology of the Berlin University of Technology is gratefully acknowledged. J. K. is a recipient of a PhD scholarship of the Berliner Programm zur Förderung der Chancengleichheit für Frauen in Forschung und Lehre, M. Y. A. of a doctoral fellowship of the University of Aleppo, Syria.

\section{REFERENCES}

Bae, T. \& Dunny, G. M. (2001). Dominant-negative mutants of $\operatorname{prgX:}$ evidence for a role for $\operatorname{PrgX}$ dimerization in negative regulation of pheromone-inducible conjugation. Mol Microbiol 39, 1307-1320.

Bae, T., Kozlowicz, B. K. \& Dunny, G. M. (2002). Two targets in pCF10 DNA for PrgX binding: their role in production of $\mathrm{Qa}$ and prgX mRNA and in regulation of pheromone-inducible conjugation. J Mol Biol 315, 995-1007.

Bae, T., Kozlowicz, B. K. \& Dunny, G. M. (2004). Characterization of cis-acting $\operatorname{prg} Q$ mutants: evidence for two distinct repression mechanisms by Qa RNA and $\operatorname{PrgX}$ protein in pheromone-inducible enterococcal plasmid pCF10. Mol Microbiol 51, 271-281.

Cascales, E. \& Christie, P. J. (2003). The versatile bacterial type IV secretion systems. Nat Rev Microbiol 1, 137-149.

Chandler, J. R. \& Dunny, G. M. (2004). Enterococcal peptide sex pheromones: synthesis and control of biological activity. Peptides 25, 1377-1388.

Chang, A. C. Y. \& Cohen, S. N. (1978). Construction and characterization of amplifiable multicopy DNA cloning vehicles derived from the P15A cryptic miniplasmid. J Bacteriol 134, 1141-1156.

Christie, P. J. (2004). Type IV secretion: the Agrobacterium VirB/ D4 and related conjugation systems. Biochim Biophys Acta 1694, 219-234.

Christie, P. J. \& Cascales, E. (2005). Structural and dynamic properties of bacterial type IV secretion systems. Mol Membr Biol 22, 51-61.

Christie, P. J., Atmakuri, K., Krishnamoorthy, V., Jakubowski, S. \& Cascales, E. (2005). Biogenesis, architecture, and function of bacterial type IV secretion systems. Annu Rev Microbiol (in press).

Clewell, D. B. \& Dunny, G. M. (2002). Conjugation and genetic exchange in Enterococci. In The Enterococci: Pathogenesis, Molecular Biology, and Antibiotic Resistance, 1st edn, pp. 265-300. Edited by M. S. Gilmore, D. B. Clewell, P. Courvalin, G. M. Dunny, B. E. Murray \& L. B. Rice. Washington, DC: American Society for Microbiology.

de Antonio, C., Farías, M. E., de Lacoba, M. G. \& Espinosa, M. (2004). Features of the plasmid pMV158-encoded MobM, a protein involved in its mobilization. J Mol Biol 335, 733-743.

Farias, M. E., Grohmann, E. \& Espinosa, M. (1999). Expression of the mobM gene of the streptococcal plasmid pMV158 in Lactococcus lactis subsp. lactis. FEMS Microbiol Lett 176, 403-410.

Frost, L. S. \& Manchak, J. (1998). $\mathrm{F}^{-}$phenocopies: characterization of expression of the $\mathrm{F}$ transfer region in stationary phase. Microbiology 144, 2579-2587.

Grohmann, E. (2005). Cell-cell channels in conjugating bacteria. In Cell-Cell Channels. Edited by F. Baluska, D. Volkmann \& P. W. Barlow. Georgetown, TX: Landes Bioscience (in press).

Grohmann, E., Guzmán, L. M. \& Espinosa, M. (1999). Mobilisation of the streptococcal plasmid pMV158: interactions of MobM protein with its cognate oriT DNA region. Mol Gen Genet 261, 707-715.

Grohmann, E., Muth, G. \& Espinosa, M. (2003). Conjugative plasmid transfer in Gram-positive bacteria. Microbiol Mol Biol Rev 67, 277-301.

Hayes, W. (1964). The Genetics of Bacteria and their Viruses. New York: Wiley.

Horii, T., Nagasawa, H. \& Nakayama, J. (2002). Functional analysis of TraA, the sex pheromone receptor encoded by pPD1, in a promoter region essential for the mating response in Enterococcus faecalis. J Bacteriol 184, 6343-6350.

Horodniceanu, T., Bouanchaud, D. H., Bieth, G. \& Chabbert, Y. A. (1976). R plasmids in Streptococcus agalactiae (group B). Antimicrob Agents Chemother 10, 795-801. 
Jacob, A. E. \& Hobbs, S. J. (1974). Conjugal transfer of plasmidborne multiple antibiotic resistance in Streptococcus faecalis var. zymogenes. J Bacteriol 117, 360-372.

Kopeć, J., Bergmann, A., Fritz, G., Grohmann, E. \& Keller, W. (2005). TraA and its N-terminal relaxase domain of the Gram-positive plasmid pIP501 show specific oriT binding and behave as dimers in solution. Biochem J 387, 401-409.

Kurenbach, B., Grothe, D., Farías, M. E., Szewzyk, U. \& Grohmann, E. (2002). The tra region of the conjugative plasmid pIP501 is organized in an operon with the first gene encoding the relaxase. J Bacteriol 184, 1801-1805.

Kurenbach, B., Bohn, C., Prabhu, J., Abudukerim, M., Szewzyk, U. \& Grohmann, E. (2003). Intergeneric transfer of the Enterococcus faecalis plasmid pIP501 to Escherichia coli and Streptomyces lividans and sequence analysis of its tra region. Plasmid 50, 86-93.

Leblanc, B. \& Moss, T. (1994). Dnase I footprinting. In DNA-Protein Interactions, Principles and Protocols (Methods in Molecular Biology vol. 30), pp. 1-10. Edited by G. G. Kneale. Tatowa, NJ: Humana Press.

Llosa, M. \& de la Cruz, F. (2005). Bacterial conjugation: a potential tool for genomic engineering. Res Microbiol 156, 1-6.

Miller, J. H. (1972). Experiments in Molecular Genetics, 1st edn. Cold Spring Harbor, NY: Cold Spring Harbor Laboratory.

Ronald, S. L., Kropinski, A. M. \& Farinha, M. A. (1990). Construction of broad-host-range vectors for the selection of divergent promoters. Gene 90, 145-148.
Sambrook, J., Fritsch, E. F. \& Maniatis, T. (1989). Molecular Cloning: a Laboratory Manual, 2nd edn. Cold Spring Harbor, NY: Cold Spring Harbor Laboratory.

Schulein, R., Guye, P., Rhomberg, T. A., Schmid, M. C., Schroder, G., Vergunst, A. C., Carena, I. \& Dehio, C. (2005). A bipartite signal mediates the transfer of type IV secretion substrates of Bartonella henselae into human cells. Proc Natl Acad Sci U S A 102, 856-861.

Szpirer, C. Y., Faelen, M. \& Couturier, M. (2001). Mobilization function of the pBHR1 plasmid, a derivative of the broad-host-range plasmid pBBR1. J Bacteriol 183, 2101-2110.

van der Lelie, D., Wösten, H. A., Bron, S., Oskam, L. \& Venema, G. (1990). Conjugal mobilization of streptococcal plasmid pMV158 between strains of Lactococcus lactis subsp. lactis. J Bacteriol 172, 47-52.

Wang, A. \& Macrina, F. L. (1995a). Streptococcal plasmid pIP501 has a functional oriT site. J Bacteriol 177, 4199-4206.

Wang, A. \& Macrina, F. L. (1995b). Characterization of six linked open reading frames necessary for pIP501-mediated conjugation. Plasmid 34, 206-210.

Zuker, M. (2003). MFold web server for nucleic acid folding and hybridization prediction. Nucleic Acids Res 31, 3406-3415.

Zuniga, M., Pardo, I. \& Ferrer, S. (2003). Conjugative plasmid pIP501 undergoes specific deletions after transfer from Lactococcus lactis to Oenococcus oeni. Arch Microbiol 180, 367-373. 